\title{
Virtual Fieldtrips and Climate Change Education for Tourism Students
}

Christian Schott

Victoria Business School

Victoria University of Wellington

Wellington, New Zealand

christian.schott@vuw.ac.nz

DOI: https://doi.org/10.1016/j.jhlste.2017.05.002

\begin{abstract}
While the pedagogical benefits of fieldtrips have long been recognised our ever increasing understanding of the impacts of flying on climate change is presenting educators with a poignant dilemma; the many benefits long associated with international fieldtrips are at odds with the world community's needs in limiting/halting climatic change. In response, the paper presents the concept of a VRbased virtual fieldtrip as an innovative and carbon-sensitive type of (educational) travel. The paper not only makes the case for virtual fieldtrips as a meaningful learning tool but also explores both the virtual fieldtrip's impact on Greenhouse Gas emissions and climate change-related learning. On both accounts the initial findings in this paper are very encouraging. More in-depth research is now required to not only develop a deeper understanding of the full breadth of benefits, but also of the diverse weaknesses presented by virtual fieldtrips and how to negotiate them.
\end{abstract}

Keywords: tourism education, virtual fieldtrips, climate change, Fiji, experiential learning, digital immersion 


\section{Introduction}

Experiential learning has been a strong component of tourism and hospitality disciplines for many decades. Prominent examples are work placements, teaching restaurants and kitchens, and fieldtrips. They are regarded as valuable opportunities for students to bridge theory and practice by learning in and from the 'real world'. Traditionally, fieldtrips have been commonly used to study both tourism and hospitality topics in a meaningful setting; both domestically and internationally. However, over the last decade awareness and research about the impacts of travel on the climate system has increased rapidly. Numerous studies (Amelung, Nichols, \& Viner, 2007; Becken \& Hay, 2007; Scott, Hall, \& Gössling, 2012; UNWTO, UNEP, \& WMO, 2008) have highlighted a wide range of predominantly negative impacts that are occurring and expected to worsen if the world maintains or even increases its use of fossil-fuel powered transport. As such, we face a very real dilemma in that the many benefits long associated with international fieldtrips are at odds with the world community's current as well as future needs in limiting/halting climatic change.

While small island developing nations such as Fiji are highly relevant for learning about the need as well as complexities of sustainable tourism development these same countries are particularly vulnerable to climate change impacts (IPCC, 2014). This is due to their high economic dependency on tourism (Nowak \& Sahli, forthcoming), which is expected to be heavily impacted by changes in travel patterns away from the equator (Amelung, Nicolls \& Viner, 2007), coupled with only a low adaptive capacity to deal with the negative direct and indirect impacts of climate change (Schott, Reisinger, \& Milfont, 2010).

In the face of the negative of impacts of air travel in particular new, innovative approaches are needed to allow students to learn from other countries and cultures without contributing to the significant challenges posed by climate change. It is worth noting that the fieldtrip tradition is also being challenged by organisational dynamics including financial constraints (Stainfield, Fisher, Ford, \& Solem, 2000), concerns about liability issues (Pearson \& Beckham, 2005), and reluctance by staff to 
coordinate and supervise residential fieldtrips due to work load pressures (Dredge \& Schott, 2013). Not surprisingly, innovative approaches are promoted in advancing both the sustainable tourism agenda (Bramwell \& Lane, 2012) as well as in addressing the extensive and serious challenges of climate change (Urry, 2011).

Against this background, this paper proposes an innovative revision to the long standing tradition of fieldtrips, which offers considerable potential to: (a) reduce tourism-related Greenhouse Gas (GHG) emissions and (b) deepen students' understanding of climate change. The technological innovation at the heart of this new opportunity is virtual reality (VR) software which originates from computer and gaming design. The innovative application of such technology to education and the challenges faced by climate change is the topic of this paper. Specifically, the paper discusses the opportunities that advanced virtual reality software offers for the development of a 'virtual fieldtrip' as a valuable, carbon sensitive way of learning about unfamiliar destinations and climate change. The paper is guided by four sequential aims:

- Present the concept of a VR-based virtual fieldtrip as an experiential learning tool for Sustainable Tourism Management Education (incorporating climate change education)

- Highlight a range of educational benefits offered by a VR-based virtual fieldtrip

- Examine the GHG emissions-related benefits of a virtual fieldtrip for a class of 91 undergraduate students when compared with a real fieldtrip

- Explore evidence of climate change-related learning in student work conducted as part of the virtual fieldtrip

After a review of the literature dealing with experiential learning, digital immersion in education, and finally education about climate change a virtual fieldtrip project for undergraduate Tourism Management students in New Zealand will be presented to make the case for its place in today's tertiary (tourism) education. Subsequently, the important differences in GHG emissions between a 
virtual and a real fieldtrip will be examined before an initial exploration of impacts on learning is presented by examining reflective student essays for evidence of climate change-related learning.

\section{Literature Review}

\section{Experiential learning and fieldtrips}

Experiential learning is a theory based on the work of influential $20^{\text {th }}$ century thinkers including John Dewey, Kurt Lewin, Jean Piaget, William James, Carl Jung, Paulo Freire, Carl Rogers and others (Kolb \& Kolb, 2005). The theory defines learning as "the process whereby knowledge is created through the transformation of experience. Knowledge results from the combination of grasping and transforming experience" (Kolb, 1984: 41). Six principles underlie the theory (Kolb, 1984):

1. Learning is best conceived as a process, not in terms of outcomes.

2. Learning is best facilitated by a process that draws out beliefs and ideas about a topic so that they can be examined, tested, and integrated with new, more refined ideas.

3. In the process of learning one is called upon to move back and forth between opposing modes of reflection and action and feeling and thinking. Conflict, differences, and disagreement are what drive the learning process.

4. Learning is a holistic process involving the total person - thinking, feeling, perceiving, and behaving.

5. Learning results from synergetic transactions between the person and the environment.

6. Learning is the process of creating knowledge; experiential learning theory is based on a constructivist theory of learning.

Educational philosopher John Dewey has long promoted fieldtrips as a powerful type of experiential learning that solidly embraces the six principles. He further notes "nothing takes root in mind when there is no balance between doing and receiving. Some decisive action is needed in order to establish contact with the realities of the world and in order that impressions may be so related that their value is tested and organised (Dewey, 1934:45 in Kolb \& Kolb, 2005). Research on experiential learning 
highlights effective bridging of theory and practice at a depth that cannot be gained through books and lectures alone (Wright, 2000) and Scarce (1997) found that fieldtrips allow students to engage actively in both testing and generating theories. Importantly, experiential learning suites a variety of learning styles and draws on active learning which has been highlighted as a valuable means of engaging students with the subject (Hanson \& Moser, 2003; Schott \& Sutherland, 2008), enhancing student's knowledge of the subject (Chickering \& Gamson, 1987), as well as assisting to develop lifelong learners (Grabinger \& Dunlap, 1995). Fieldtrips also place students in a meaningful physical and socio-cultural context which adds additional layers to the learning experience in the form of situated learning, which has been credited with assisting to crystallise learning outcomes (Jakubowski, 2003; Scarce, 1997). Hence, the merit of fieldtrips, in particular to environments that are culturally, ecologically and socially unfamiliar, is well established.

Although fieldtrips are used to examine a wide range of topics, it is not uncommon for the focus to be related to conservation or sustainability topics. Herein lies a poignant dilemma. To allow for the aboveoutlined rich and meaningful learning to take place, staff and students commonly use fossil fuelpowered transport to reach the site/s of the fieldtrip. In a nutshell, to learn about important issues such as sustainable development or climate change in a pertinent context in another country the fieldtrip group contributes to the issue under study through the burning of fossil fuels during their flight to the destination.

While some may argue that offsetting the fieldtrip's GHG emissions is an option for decreasing its contribution to climate change, this appears to happen only rarely. Anecdotally, the reasons are financial constraints as well as doubts about the integrity and/or net benefit of main-stream offsetting programs. As posited earlier, a creative approach to resolving the above outlined dilemma is offered by the concept of a 'virtual fieldtrip' which sees students conduct real fieldwork in a meaningful, virtually represented three dimensional space while remaining at the university campus. Rapid advances in virtual reality software and hardware over the last decade are at the heart of this innovation, 
which provides students the opportunity to richly learn about the diverse direct and indirect impacts of climate change in a meaningful context while minimising the related contribution to GHG emissions.

\section{Digital Immersion in Education}

Education scholars spanning many disciplines have been inspired to recreate aspects of a real fieldtrip by exploring different types and styles of situating students in the material under study and blending it with elements of active learning. Some authors refer to these educational projects as 'virtual fieldtrips'; however the term is used loosely in the reviewed publications and refers to a wide variety of learning tools ranging from multimedia maps (Krygier, 1999), Internet sites (Cooper, 1997; Crampton, 1999), a combination of tele conferencing and Internet sites (Box-Steffensmeier, Grant, Meinke, \& Tomlinson, 2000), a combination of videos, pictures and interpretative text (Turney, Robinson, Lee, \& Soutar, 2009), to earlier versions of VR integrated with multimedia (Stainfield et al., 2000) as well as virtual reality environments where physical features are observed or role plays take place (Penfold, 2009). While the use of high resolution virtual reality software appears to be increasing in an education context publications are limited. There is an absence of projects which tackle the complex issue of climate change. There is also no evidence that large-scale areas such as an entire island or village, both of which allow for a broader and more diverse learning experience, have been recreated in VR for educational purposes. In the reviewed literature there is also no evidence of group-based fieldwork taking place 'in world' (meaning between avatars while they are in the virtual environment) apart from role play in small scale medical VR scenarios. In order to portray the complexities of a destination and its communities in as realistic a context as possible it is also important to enrich, or more appropriately populate, a virtual reality environment with photographs and, most importantly, with people and their realities, stories and opinions. In summary, a 'virtual fieldtrip' is thus defined in the following way for this project:

A virtual fieldtrip recreates a wide range of aspects and complexities of the real world in digital format using both audio and visuals (3D objects, videos, still images, and documents). It allows students/researchers to digitally immerse themselves and 
collaborate in the environment (physical and social/cultural) with the aim of completing fieldwork tasks similar in nature to those set during real fieldtrips.

\section{Climate Change Education}

Despite climate change education thus far delivering only limited success as a mitigation mechanism there is no doubt that it plays a paramount role in addressing this complex issue (Bangay \& Blum, 2010; Dodds \& Kelman, 2008; Jickling, 2001; Mochizuki \& Bryan, 2015). When dissecting education as a mitigation mechanism there are two key strands, public education and formal institutional education. The former is undoubtedly important in providing the public with a solid understanding of the causes and consequences of climate change. However, when adopting a longer-term perspective formal education has greater potential as a mitigation mechanism. This belief is driven by the notion that the long term impacts of formal education are powerful in influencing decision-making and behaviour beyond the years spent in formal education; as for example demonstrated by Hoskins, D'Hombres, and Campbell (2008) in the context of socially-focused active citizenship. But it needs to be acknowledged that climate change is a complex process (Bangay \& Blum, 2010; Schreiner, Henriksen, \& Hansen, 2005). Consequently climate change education not only requires extensive examination of the key dynamics and features, but also a learning environment that allows students to effectively crystalise the key dynamics as well as the complexities at play. Not surprisingly, Pruneau, Gravel, Bourque, and Langis (2003) promote fieldtrips as an important tool for climate change education.

When exploring the key principles or goals of climate change education it becomes evident that there is a lack of consensus across the many disciplines that teach climate change. However, when focusing on the broadest goals of climate change education the following components can be synthesised (Forest \& Feder, 2011): improving understanding of climate-related issues (climate systems, climate change, and the impacts of climate change), raising awareness of the potential strategies for limiting the impacts of climate change (mitigation and adaptation), encouraging specific action to minimize human impacts 
and adapt to the changing climate, and helping individuals and groups to make climate-friendly choices. This basic framework of climate change-related learning will be enlisted when exploring the reflective essays for evidence of climate change related learning. The paper will now provide a brief overview of the virtual fieldtrip learning tool and the associated learning task.

\section{The Virtual Fieldtrip: Design and Development}

Although many places would be suitable destinations for the virtual fieldtrip, Fiji was selected due to two key considerations. From both a sustainable tourism development and climate change perspective Fiji is an appropriate setting for a fieldtrip because the country and its many islands are vulnerable to sea level rise and storm surge, changing temperature and precipitation patterns, as well as extreme weather events (Becken, 2005). From a tourism perspective Fiji is also suitable as it is the third most visited country by New Zealanders (Statistics New Zealand, 2016) and as such a place of great relevance to undergraduate Tourism Management students in New Zealand (which is where the students who used the virtual fieldtrip are located) - both as current tourists and as future managers in the tourism and hospitality industry in Asia Pacific.

To allow for the best available software option to be enlisted the first project phase consisted of identifying all suitable software programmes. From this search ten were shortlisted and assessed against a set of nine criteria (see Schott (2015) for details); Open Simulator, an open source version of the popular virtual world programme 'Second Life' was selected as the most suitable. With a list of desired learning components coupled with a clear understanding of the capabilities and information needs of the software program the project leader and a cultural Research Assistant (RA) travelled to a Fijian island to gather the necessary material and information for the project. In addition to an identified need to examine the broader direct and indirect impacts of climate change, the implications of these impacts for communities and their way of life was also regarded as an important perspective for students. Guided by the aspiration to add a human layer the technical RA embedded audio- 
supported videos at appropriate places on the virtual island to allow students to 'meet' the community members and to ultimately bring the island to live.

Climate Change and related aspects featured in a variety of ways in the virtual fieldtrip. Three community members with roles that included village-wide responsibilities were invited during the development visit to talk about any challenges that the island and its communities were facing. This was seen as an important perspective to allow students to learn about interrelationships and tensions, and was subsequently embedded in the programme in the form of videos. Although the question was very broad and one of only three questions posed, climate change and its impact were mentioned by two of these senior figures - one from each village. The fact that they talk about climatic changes affecting the island as well as the community's everyday life illustrates to the students that climate change (already) has very real implications on this island; this is valuable as students are often exposed to PPT slides filled with abstracts graphs, charts and projections as part of their tertiary climate change education. The opportunities to connect directly with community members (through videos which are watched in world at the same location where they were recorded) and learn about their experiences and concerns are considered valuable in adding relevance and a greater sense of urgency to a topic that is dominated by scientific interpretations and projections, and is often perceived as both complex and hypothetical in nature (Reisinger, 2009; Swim et al., 2009).

A poignant quote about climatic changes and their impacts was made by the Village Headman (caretaker role) of one village:

"The issue of climate changes is one that touches the heart of this village. We have noticed a lot of changes in the weather for this island. The island is generally dry, sunny.....However, we have been experiencing a lot of rain that has ruined a lot of root crops and plantations. It has also brought mosquitoes, which was something that we never experienced here." 
The spokesman (leadership role when chief is absent) for the other village elaborates on the impact of these climatic changes on the crops, which are indispensable on these islands.

"There are changes in weather or climate that affect things such as Yams. This (in June) is yam season, but the soil has been too wet which is not good for planting. It is still raining now and it shouldn't. In the past, the weather was never like this. It is usually dry at this time in the past"

These are powerful statements because village life on this remote island relies heavily on subsistence farming, which alongside fishing, provides the main food source. The detrimental impacts of climate change on existing food supplies have been highlighted by a number of publications (Easterling et al., 2007; Rosenzweig \& Parry, 1994) and scarcity or oversupply of water is considered a key factor. Similarly concerning is the arrival of mosquitos in the first village due to increased humidity and more wet areas. Health studies have identified these factors to be linked to incidences of diseases such of malaria, rift valley fever and dengue fever in various parts of the world (Patz, Campbell-Lendrum, Holloway, \& Foley, 2005). The higher level of humidity has also been documented to increase diarrheal disease in Pacific Island Countries (Singh, Hales, de Wet, Raj, Hearnden, \& Weinstein, 2001). Although neither of these specific issues were explicitly communicated to the students, both the expected direct and direct impacts of climate change were discussed in the lectures and readings before 'departing' on the virtual fieldtrip.

The spokesperson for the second village highlights that the village is also intimately aware of the destruction that severe tropical storms and storm surges can bring to the island.

"Well, we are back here in the original site for our village first settled by our ancestors. In 1952 we were badly hit by this big hurricane that decimated our village. It destroyed every house leaving none standing. The whole village was then immediately flooded by a big wave that forced a relocation of the village to a site along the bay".

To the great concern of many communities living on low lying islands in the Pacific, such as these, tropical cyclones are expected to increase in severity under most emission scenarios (IPCC, 2007) and 
storm surges are rendered more destructive by the compounding effect of slow but steady sea level rise (IPCC, 2007; Knutson et al., 2010). While the destructive storm in 1952 may not be attributable to the more pronounced climatic changes observed over the last decades, the vulnerability of these villages to storm surges and flooding, in addition to the points highlighted earlier, is render crystal clear by the interviews. The realisation that communities in developing countries are often already experiencing noticeable climate change impacts due to significant vulnerability is an important learning outcome for students in New Zealand, where climate change impacts are currently less evident than in Fiji because of the New Zealand's comparably lower overall vulnerability (Notre Dame Global Adaptation Index, 2014).

\section{The real fieldwork: learning scenario and student task}

The learning scenario was designed to deepen students' understanding of sustainable tourism development and its underlying theories by exposing them to the complexities, realities and tensions commonly observed in developing countries. Climate change is an important consideration in this scenario because it is a significant dynamic in the context of sustainable development (Lane, 2009; Mochizuki \& Bryan, 2015) and it is of great current and future relevance to low-lying islands; in particular in developing countries. To retain the paper's focus on climate change, both in terms of the impacts of educational travel as well as climate change learning, it will discuss the student tasks related to climate change rather than the broader concepts of sustainable tourism development.

The following role play scenario was developed for students at a New Zealand university taking a second year course on Sustainable Tourism Development. The role play consisted of four students working in a project team for Synergy Tourism Consultants (fictional) which specialise in sustainable tourism development. The team had secured a contract to work on a (fictional) collaborative initiative between the Government of Fiji and NZ Aid to determine whether strategic sustainable tourism development of a remote Fijian island would result in the positive impacts or the negative impacts (economic, environmental, socio-cultural) outweighing the other. As part of this fieldwork task 
students were exposed to information about climate change and its interrelationship with both the island and its communities. Students were advised to 'weave' what they had learned in the lectures and readings into the learning taking place during the virtual fieldtrip. As is the case for a real fieldtrip the students also received a project file with information about the island, the task and the related assessment requirements at the beginning of the project.

Students started their visit to the virtual island at the same point where boats arrive on the real island and subsequently proceeded to the Community Hall in the centre of the village to 'virtually' meet the community as part of the customary Fijian 'I sevusevu' (welcoming) ceremony; by watching an 'inworld' video of the ceremony. After this key piece of Fijian cultural protocol was satisfied, students set off on their fieldwork. Subsequently, each project team had to decide whether they supported tourism development on the island or whether they would argue against tourism development. The teams working on a sustainable tourism development proposal had to address five key criteria, while the teams proposing that no development should take place were asked to discuss the rationale behind their decision by distinguishing between economic, environmental, and socio-cultural reasons. Following each group's construction of a wiki to present the groups' findings and recommendations all students were required to write an individual reflective essay on this topic: reflect on how the fieldwork on the virtual island impacted on your learning (catalysts and challenges) and critically assess how such technology could be used by the tourism industry. The motivation for the reflective task was to encourage students to consciously examine how they learn most effectively and meaningfully in terms of longer term learning. The second part of the task was designed to encourage students to think creatively about the use of this technology in other applied contexts.

\section{Methodology}

While the two main aims of this paper, to conceptualise virtual fieldtrips in an era of VR and to make the case for virtual fieldtrips in the context of tourism education, were addressed on the previous pages, the last two aims contain research components which deserve elaboration. In pursuit of the third aim, 
which is to calculate the GHG-related implications of virtual fieldtrips compared to real fieldtrip, a publically-accessible carbon calculator (CarboNZero) was utilised in addition to key reports. While the calculator is furnished with scientifically-generated data (see details on http://www.enviromark.com/home), the calculations in this paper are not intended to be scientific. Instead, indicative findings that broadly illustrate the difference are considered sufficient.

The final aim explored evidence of climate change-related learning in the reflective essays of students in this $2^{\text {nd }}$ year course. In accordance with the institution's research ethics guidelines a third Research Assistant was hired to assist with the handling of the reflective essays. After the conclusion of the course the Research Assistant contacted the 91 enrolled students seeking permission to use the reflective essays for research purposes. Of the 91 students who participated in the virtual fieldtrip 67 gave permission for their reflections to be used (however four reflections could not be located), one student refused permission and the remaining students did not reply or could not be contacted; thus, 63 reflective essays formed the basis of this exploratory examination.

As outlined earlier, the task for the reflective essay was broad and there was no mention of climate change or closely-related terminology in the wording of the task. Each reflective essay was read twice for the purpose of identifying evidence of climate change related learning. By adapting the categories proposed by Forest and Feder (2011) for the purpose of this exploratory examination the extracted quotes were subsequently arranged under the following headings: (i) understanding of climate systems and climate change, (ii) direct and indirect impacts of climate change, (iii) awareness of the potential strategies for limiting the impacts of climate change (mitigation and adaptation); (iv) encouraging specific action to minimize human impacts and adapt to the changing climate, and (v) helping individuals and groups to make climate-friendly choices. 


\section{Exploratory Findings}

\section{GHG emissions from virtual and real fieldtrip}

The calculations in Table 1 represent the main emissions identified; other emissions are marginal and subject to debate. It is worth noting that unlike other research which examined travel emissions for a particular event or activity (Becken, 2002) the calculations in this paper include a radiative forcing multiplier for the flight component to account for the oxides of nitrogen and water vapour emitted, which can have an impact on atmospheric temperature (Sausen et al., 2005).

\section{Virtual Fieldtrip -}

Emissions-related activities including real fieldwork by two staff to gather all required information as well as student and staff utilisation of virtual fieldtrip programme

\begin{tabular}{|c|c|c|c|}
\hline Activity Type & $\begin{array}{l}\text { No. of } \\
\text { people }\end{array}$ & Activity Specifics & $\begin{array}{l}\text { Total } \mathrm{CO}_{2}-\mathrm{e} \\
\text { Emissions }\end{array}$ \\
\hline Return Flight NZ to Nadi (Fiji) & 2 & Return distance $5253 \mathrm{~km}$ & $2425.36 \mathrm{Kg}$ \\
\hline Return water transport port to island & 2 & Return distance $238 \mathrm{~km}$ (straight line) & $115.6 \mathrm{~kg}$ \\
\hline Road Transport in New Zealand & 2 & $\begin{array}{l}20 \mathrm{~km} \text { (average) return to airport with } \\
\text { occupancy } 1 \text { staff per car }\end{array}$ & $9.52 \mathrm{~kg}$ \\
\hline Road Transport in Fiji & 2 & $\begin{array}{l}20 \mathrm{~km} \text { return in taxi from Nadi airport to } \\
\text { Denerau Port }\end{array}$ & $9.52 \mathrm{~kg}$ \\
\hline $\begin{array}{l}\text { Four nights' Accommodation on } \\
\text { island }\end{array}$ & 2 & No electricity in village accommodation & $0 \mathrm{~kg}$ \\
\hline One night in hotel en route to island & 2 & Generic (not Fiji specific) calculator formula & $15.94 \mathrm{~kg}$ \\
\hline $\begin{array}{l}\text { Electricity for computers and } \\
\text { monitors }\end{array}$ & 96 & $\begin{array}{l}\text { Average use by students } 6.6 \text { hours with } \\
\text { average energy consumption (processor and } \\
\text { monitor) } 0.09 \mathrm{kwh} \text { (Wilkes, 2012) and } \mathrm{CO}_{2}-\mathrm{e} \\
\text { Emissions } 0.137 \mathrm{~kg} \text { per } \mathrm{kwh} \\
\text { (Ministry for the Environment, 2011) }\end{array}$ & $7.81 \mathrm{~kg}$ \\
\hline \multicolumn{3}{|c|}{ Total estimate for virtual fieldtrip $\mathrm{CO}_{2}$-e Emissions } & $2583.75 \mathrm{~kg}$ \\
\hline
\end{tabular}

Real Fieldtrip

Emissions-related activities for 91 students accompanied by about five staff members

\begin{tabular}{|l|r|l|c|}
\hline \multicolumn{1}{|c|}{ Activity Type } & $\begin{array}{c}\text { No. of } \\
\text { people }\end{array}$ & Activity Specifics & $\begin{array}{c}\text { Total CO2-e } \\
\text { Emissions }\end{array}$ \\
\hline Return Flight NZ to Nadi (Fiji) & 96 & Return distance $5253 \mathrm{~km}$ & $116417.28 \mathrm{Kg}$ \\
\hline Return water transport port to island & 96 & Return distance 238km (straight line) & $5549.76 \mathrm{~kg}$ \\
\hline Road Transport in New Zealand & 96 & $\begin{array}{l}\text { 20 km (average) return to airport with average } \\
\text { occupancy 1.5 students } / \text { staff per car }\end{array}$ & $342.72 \mathrm{~kg}$ \\
Road Transport in Fiji & 96 & & $68.16 \mathrm{~kg}$ \\
\hline
\end{tabular}




\begin{tabular}{|c|c|c|c|}
\hline & & $\begin{array}{l}20 \mathrm{~km} \text { return on bus from Nadi airport to } \\
\text { Denerau Port }\end{array}$ & \\
\hline $\begin{array}{l}\text { Four nights' accommodation on } \\
\text { island } \\
\text { One night in hotel en route to island }\end{array}$ & 96 & $\begin{array}{l}\text { No electricity in village accommodation } \\
\text { Emissions figure overstated because large } \\
\text { groups create larger energy efficiencies than } \\
\text { average guest nights used by calculator }\end{array}$ & $\begin{array}{r}0 \mathrm{~kg} \\
764.75 \mathrm{~kg}\end{array}$ \\
\hline \multicolumn{3}{|c|}{ Total estimate for real fieldtrip $\mathrm{CO}_{2}-\mathrm{e}$ Emissions } & 123142.67 \\
\hline
\end{tabular}

Note: With the exception of the electricity calculation for computer and monitor use, the above calculations are based on Landcare Research/Manaaki Whenua's CarboNZero Travel \& Tourism Calculator. Landcare Research/Manaaki Whenua is a Crown Research Institute owned by the New Zealand Government. The CarboNZero Travel \& Tourism Calculator uses a radiative forcing factor of 1.9 for air travel (to reflect the global warming potential of oxides of nitrogen that are emitted into the lower and upper atmospheres); see Sausen et al (2005) for details about why this multiplier deviates from the common multiplier of 2.7. For more detail about the CarboNZero calculator's methodology see http://www.carbonzero.co.nz/help.asp\#transport

Table 1. Calculation of $\mathrm{CO}_{2}$-e emissions from virtual fieldtrip and real fieldtrip

Table 1 highlights that the indicative $\mathrm{CO}_{2}$ equivalent $\left(\mathrm{CO}_{2}-\mathrm{e}\right)$ emissions from a real fieldtrip to Fiji for 91 students and 5 staff amount to about 123 tonnes, while the indicative emissions generated by the virtual fieldtrip for the class amount to about 2.6 tonnes. The difference then equates to about 120 tonnes of $\mathrm{CO}_{2}$-e emissions, or in other words the virtual fieldtrip generated roughly $1 / 47^{\text {th }}$ of the real fieldtrip's estimated emissions in the first year it is run. This significant difference in GHG emissions is further magnified by the fact that the virtual fieldtrip can be used with subsequent cohorts of students without the renewed need for staff to physically travel to the island; unless changes or developments occur on the real island which require incorporation into the virtual island.

In the face of behavioural mitigation mechanisms struggling to make a significant impact (Lorenzoni, Nicholson-Cole, \& Whitmarsh, 2007), product innovations, such as VR (learning) experiences, are worth exploring in greater detail. However, it needs to be noted here that this paper does not propose that traditional residential fieldtrips can simply be replaced by virtual fieldtrips while achieving the same outcomes. Instead, the paper posits that students conducting fieldwork on a virtual fieldtrip are exposed to some of the valuable educational nuances of real fieldtrips, most notably the benefits that arise from experiential and situated learning in a complex but integrated environment. For the sake of argument the following question could be posed: in view of the virtual fieldtrip's GHG emission 
equating to a fraction of a real fieldtrip, do the learning outcomes reached by the students equally equate to only a fraction of the ones achieved on a real fieldtrip to Fiji? While answering such a detailed question is not the purpose of this paper, the subsequent examination of the reflective essays provides initial evidence that meaningful learning about climate change takes place as part of the virtual fieldtrip.

\section{Climate change-related student learning}

Initially, it is worth noting that while reflections made reference to the issues presented by the village leaders, some students also exhibited the ability to extend on these concerns by creating clear learning connections to the climate change related material studied earlier in the course. As highlighted in the methods section the findings distinguish between five layers of learning about climate change: (i) understanding of climate systems and climate change, (ii) direct and indirect impacts of climate change, (iii) awareness of the potential strategies for limiting the impacts of climate change (mitigation and adaptation); (iv) encouraging specific action to minimize human impacts and adapt to the changing climate, and (v) helping individuals and groups to make climate-friendly choices. Quotes from the reflective essays are used to display the students' thoughts in their full richness; implications from the findings as well as the broader thrust of this paper will be discussed in the concluding section.

\section{Understanding of climate systems and climate change}

Four students discussed increased understanding of climate change and in particular how the virtual fieldtrip can foster such understanding. Due to the phrasing of the question it is not surprising that students extended their understanding of climate change to the virtual fieldtrip (as a tool that holds great potential in this context). In fact, the below quote underscores the very motivation for this paper in highlighting the benefits of virtual fieldtrips in the context of climate change education.

"this technology can be used to increase the awareness of problems occurring at destinations including climate change...people will be able to interact and gain better 
understanding of the problem from hearing it through the host community and seeing images. "

\section{Direct and indirect impacts of climate change}

Under direct and indirect impacts of climate change two streams were observed, one consisted of comments about learning about impacts while the other dealt with the related issue of vulnerability. Six students highlighted an understanding of climate change impacts in their reflections. The comments covered both the impacts that occur as well as those that can be avoided through effective management of the causes. The discussed impacts were predominantly related to impacts on the natural environment, but included both natural resources as well as physical natural environments. Although, vulnerability to climate change was referred to by a smaller group of students (3) the reference to this concept was considered a valuable finding as the concept was not explicitly addressed in the lectures and readings prior to the virtual fieldtrip. These comments then provide initial evidence of the virtual fieldtrip serving the important role of supporting the extension of learning beyond the material covered in class through the holistic and complex experience that students are exposed to on the virtual island; this aligns with the experiential learning principle that learning results from synergetic transactions (Kolb, 1984).

"by being able to see the poor condition of the water supply and their food supplies I was able to further my understanding”,

\section{Awareness of the potential strategies for limiting the impacts of climate change}

The most significant evidence of climate change-related learning was observed under this category as 13 students mentioned mitigation or adaptation in their reflections. Because the virtual fieldtrip can itself be framed as a mitigation option, as argued in Table 1, it is not surprising that the great majority of reflections discussed mitigation. On the other hand, only one student discussed climate change adaptation by highlighting the need to adapt through careful management of fresh water resources. The many comments about climate change mitigation acknowledged the benefits of the virtual fieldtrip 
in allowing students to learn about an island, its community, everyday life, and key challenges while emphasising that there was no need to travel to the actual island.

“numerous tourism management students were able to utilize this technology and explore an island in Fiji instead of increasing carbon emissions by travelling to the destination"

\section{Encouraging specific action to minimize human impacts and adapt to the changing climate}

Although only one student discussed learning related to this topic, it is encouraging that the student was able to 'digest' what he/she learned at an advanced level and able to formulate a focused recommendation. For students to apply the learning outcomes generated by the virtual fieldtrip to their subject knowledge of tourism management is one of the established benefits of fieldtrips (Fuller, 2006); in this case the knowledge transfer allows for complex and multi-layered mitigation strategies to be formulated.

"Virtual technology can be used as a planning tool.... to develop a sustainable tourism scenario that mitigates the impact of climate change."

The reference to 'planning tool' highlights that the student adopts a forward thinking approach which is a critical part of tourism management education (Sheldon, Fesenmaier, \& Tribe, 2011). Equally, 'scenario' and 'mitigation' illustrate that the student recognises the need to adopt a broader approach to addressing the challenges posed by climate change. Too often is there a tendency to adopt a narrowly-focused approach which is likely to limit options for solutions and may negate opportunities for synergies to be created.

Explicit evidence of learning was not identified in the context of the final goal of climate change education as proposed by Forest and Feder (2011): helping individuals and groups to make climatefriendly choices; this was considered neither surprising nor concerning due to the nature and focus of the virtual fieldtrip and reflective essay. Other learning tools with a greater focus on consumer decision-making are considered more appropriate to foster this learning goal. 


\section{Discussion and Conclusions}

The paper set out to make the case for virtual fieldtrips as an effective learning tool in the context of climate change education by addressing four differently focused aims. Because of the innovative use of virtual fieldtrips by embracing advanced virtual reality software and its emphasis on both cultural and spatial components, the first aim was to provide some insight into how the virtual island was developed. In this context a definition of 'virtual fieldtrip' was proposed, which incorporates features of currently available VR technology:

A virtual fieldtrip recreates a wide range of aspects and complexities of the real world in digital format using both audio and visuals (3D objects, videos, still images, and documents). It allows students/researchers to digitally immerse themselves and collaborate in the environment (physical and social/cultural) with the aim of completing fieldwork tasks similar in nature to those set during real fieldtrips.

It is acknowledged that due to the rapid pace of innovation in the context of virtual and augmented reality this definition may need to be revised in a few years' time to incorporate innovation that does not yet exist. The most obvious opportunity for extending this technology is to explore the use of virtual reality headsets, such as the Oculus Rift (Schott, Thomson, \& Marshall, 2015), and associated developments that seek to further increase the 'tourists' sense of full immersion through touch, smell or taste (Guttentag, 2010).

The second aim outlined the diverse benefits of virtual fieldtrips for learning in general, but using climate change education as a particular focus for this paper. Set against the solid educational backbone of experiential learning (Kolb, 1984), this digitally immersed type of experiential learning offers a range of pedagogical benefits including that the depth of learning offered by this learning tool cannot be obtained through books and lectures alone (Wright, 2000). Climate science researchers also value and promote the use of visualisations of climate change impacts for education, as "new immersive and interactive systems offer attractive possibilities for engagement, awareness building, 
and reaching the emotions of the viewer" (Sheppard, 2005: p.652). While Sheppard promotes visualisations for projected impacts, Nicholson-Cole (2005), while also supportive of the use of visualisations in general, raises concerns about the role of the underlying science when developing visualisations of projections. The virtual fieldwork project presented here, sought to negotiate this criticism by documenting climatic changes and related implications as they were perceived and reported by the community, rather than attempt to visualise scientific projections, which are always subject to certain levels of uncertainty (Deser, Phillips, Bourdette, \& Teng, 2012). Furthermore, while the virtual island offers illustrations (digital 3D visualisation or photographic image) of certain characteristics of the island and community, these are generally complemented by videos which express the views by different community members thus adding context to the visualisations. While the project leader and cultural RA sought to collect information about the island in an objective and researcher-removed manner, for example by recording videos of community members rather than summarising and interpreting their comments, it is acknowledged that both the selection and collection process has been influenced by their assessment of what information is relevant and what isn't.

Needless to say, although there are many potential benefits offered by the virtual fieldtrip, the proposed benefits need to be examined in detail and with a range of student cohorts across different year groups as well as cultures to generate a more nuanced understanding of both the strengths as well as the weaknesses of virtual fieldtrips for sustainability and climate change education. Equally, future research should examine the link between virtual fieldtrips as an experiential learning tool and different learning styles.

Subsequently, the paper highlighted the paradoxical relationship between educational travel to destinations for the purpose of sustainability and/or climate change education, and the GHG emission intensive practice of flying to the study destination. The significant estimated difference in $\mathrm{CO}_{2}$-e emissions produced by the two types of fieldtrips, coupled with evidence of meaningful learning, should suffice for VR-based virtual fieldtrips to be considered in response to Urry's call for innovation 
to address the extensive and serious challenges of climate change (2011); albeit with robust critical evaluation which must include the critical aspect of authenticity.

The final aim explored reflective essays about the virtual fieldtrip experience for evidence of climate change-related learning. Although the search for evidence of climate change-related learning was merely conducted at an exploratory level some interesting observations were made. Despite the fact that the reflective essay task made no mention of climate change or related terminology the reflections showed evidence of learning with respect to four of the five goals of climate change education adapted from Forest and Feder (2011).

Although numerous comments in the reflective essays explicitly linked the virtual fieldtrip to increased enjoyment of the learning process, as well as an increased understanding of the issues and inherent complexities the specific pedagogic implications of the virtual fieldtrip to Fiji will need to be explored in depth in a separate publication. Not surprisingly, motivation to learn and enjoyment of the learning process are critical to effective learning (Wlodkowski, 2011) and are therefore of particular interest to the author.

In conclusion, the paper has proposed a range of benefits offered by a VR-based virtual fieldtrip with special reference to climate change education. The weaknesses of the virtual fieldtrip have not been addressed in this paper and will require robust examination so that a balanced understanding of such learning tools and the extent of their effectiveness can be developed. As the island, its communities and the world around it evolve, the virtual island will also need to evolve through improvements and maintenance work; this may include the need to revisit the real island.

Apart from the avenues for further research outlined in the discussion there are additional areas deserving of further research, such as how local Fijian cultural paradigms and important details about characteristics of life on the island are communicated more effectively or are rendered more richly 
accessible to students. Equally, the manner in which important contextual factors and a greater variety of documents can be integrated in a meaningful way needs to be examined as does how the realism of the visualisations can be improved. The author wishes to conclude by re-emphasising that the paper does not propose that a virtual fieldtrip, as presented here, can be considered as a replacement for the rich and diverse (learning) experiences offered by a real fieldtrip; not least because of this quote about the perceived benefits from a real trip to the Pacific islands "we can get a tan". But rather, that in an era of increasing breadth and depth of knowledge about the detrimental impacts of carbon-intensive activities such as flying the concept of a virtual fieldtrip, coupled with targeted fieldwork, can provide a very valuable opportunity to foster meaningful and appropriately framed learning for students. 


\section{References}

Amelung, B, Nicholls, S, \&Viner, D. (2007). Implications of Global Climate Change for Tourism Flows and Seasonality. Journal of Travel Research, 45, 285-296.

Bangay, C., \& Blum, N. (2010). Education responses to climate change and quality: Two parts of the same agenda? International Journal of Educational Development, 30(4), 359-368.

Becken, S. (2002). The Energy Costs of the Ecotourism Summit in Quebec. Journal of Sustainable Tourism, 10(5), 454-456.

Becken, S. (2005). Harmonising climate change adaptation and mitigation: the case of tourist resorts in Fiji. Global Environmental Change, 15(4), 381-393.

Becken, S., \& Hay, J. (2007). Tourism and Climate Change: Risks and Opportunities. Clevedon: Channel View.

Box-Steffensmeier, J. M., Grant, J. T., Meinke, S. R., \& Tomlinson, A. R. (2000). Virtual Field Trips: Bringing College Students and Policymakers Together through Interactive Technology. PS: Political Science \& Politics, 33(4), 829-834.

Bramwell, B. \& Lane, B. (2012) Towards innovation in sustainable tourism research? Journal of Sustainable Tourism, 20 (1), 1-7.

Chickering, A., \& Gamson, Z. (1987). Seven principles of good practice in undergraduate education. AAHE Bulletin, 39, 3-7.

Cooper, G. (1997). Virtual Field Trips. Libraries Unlimited, P.O. Box 6633, Englewood, CO. 
Crampton, J. W. (1999). Integrating the Web and the geography curriculum: The Bosnian virtual fieldtrip. The Journal of Geography, 98(4), 155.

Deser, C., Phillips, A., Bourdette, V., \& Teng, H. (2012). Uncertainty in climate change projections: the role of internal variability. Climate Dynamics, 38(3-4), 527-546.

Dewey, J. (1963). Experience and Education (originally published 1938). New York: Collier.

Dodds, R., \& Kelman, I. (2008). How climate change is considered in sustainable tourism policies: a case of the Mediterranean islands of Malta and Mallorca. Tourism Review International, 12(1), 5770.

Dredge, D., \& Schott, C. (2013). Academic Agency and Leadership in Tourism Higher Education. Journal of Teaching in Travel \& Tourism, 13(2), 105-129.

Easterling, W., Aggarwal, P., Batima, P., Brander, K., Erda, L., Howden, S., Kirilenko, A., Morton, J., Soussana, J.-F., Schmidhuber, J.,\& Tubiello, F. (2007). Food, Fibre and Forest Products. In M. Parry, O. Canziani, J. Palutikof, P. van der Linden, \& C. Hanson (Eds.), Climate Change 2007: Impacts, Adaptation and Vulnerability. Contribution of Working Group II to the Fourth Assessment Report of the Intergovernmental Panel on Climate Change (273-313). Cambridge: Cambridge University Press.

Forest, S., \& Feder, M. A. (2011). Climate Change Education: Goals, Audiences, and Strategies: a Workshop Summary. National Academies Press. 
Fuller, I. C. (2006). What is the value of fieldwork? Answers from New Zealand using two contrasting undergraduate physical geography field trips. New Zealand Geographer, 62(3), 215-220.

Grabinger, R. S., \& Dunlap, J. C. (1995). Rich environments for active learning: A definition. Research in Learning Technology, 3(2).

Guttentag, D. A. (2010). Virtual reality: Applications and implications for tourism. Tourism Management, 31(5), 637-651.

Hanson, S., \& Moser, S. (2003). Reflections on a discipline-wide project: developing active learning modules on the human dimensions of global change. Journal of Geography in Higher Education, 27(1), 17-38.

Hoskins, B., d'Hombres, B., \& Campbell, J. (2008). Does formal education have an impact on active citizenship behaviour? European Educational Research Journal, 7(3), 386-402.

IPCC (2014). Climate Change 2014: Synthesis Report. Contribution of Working Groups I, II and III to the Fifth Assessment Report of the Intergovernmental Panel on Climate Change [Core Writing Team, R.K. Pachauri and L.A. Meyer (eds.)]. IPCC, Geneva, Switzerland, 151 pp.

IPCC (2007). Summary for Policymakers. In S. Solomon, D. Qin, M. Manning, Z. Chen, M. Marquis, K.B. Averyt, M.Tignor, \& H.L. Miller (Eds.). Climate Change 2007: The Physical Science Basis. Contribution of Working Group I to the Fourth Assessment Report of the Intergovernmental Panel on Climate Change. Cambridge: Cambridge University Press.

Jakubowski, L.M. (2003). Beyond book learning: Cultivating the pedagogy of experience through field trips. The Journal of Experiential Education, 26(1), 24-33. 
Jickling, B. (2001). Climate change, global warming, and education with uncertainties. Canadian Journal of Environmental Education, 6(1), 5-7.

Kolb, A. Y., \& Kolb, D. A. (2005). Learning Styles and Learning Spaces: Enhancing Experiential Learning in Higher Education. Academy of Management Learning \& Education, 4(2), 193-212.

Kolb, D.A. (1984). Experiential learning: experience as the source of learning and development. Englewood Cliffs, NJ: Prentice Hall.

Knutson, T. R., McBride, J.L, Chan, J., Emanuel, K., Holland, G., Landsea, C., Held, I., Kossin, J.P., Srivastava, A.K., \& Sugi, M. (2010). Tropical Cyclones and Climate Change. Nature Geoscience, 3(3), 157-63.

Krygier, J. B. (1999). Cartographic Multimedia and Praxis in Human Geography and the Social Sciences. In D. W. Cartwright, D. M. P. Peterson, \& D. G. Gartner (Eds.), Multimedia Cartography (pp. 245-255). Springer Berlin Heidelberg.

Lane, B. (2009). Thirty years of sustainable tourism: Drivers, progress, problems - and the future. In S. Gössling, C.M. Hall, \& D.B.Weaver (Eds.), Sustainable tourism futures (pp. 19-32). London: Routledge.

Lorenzoni, I., Nicholson-Cole, S., \& Whitmarsh, L. (2007). Barriers perceived to engaging with climate change among the UK public and their policy implications. Global environmental change, 17(3), 445-459. 
Ministry for the Environment (2011). Guidance for Voluntary Corporate Greenhouse Gas Reporting: Data and Methods for the 2010 Calendar Year. Wellington: Ministry for the Environment.

Ministry of Business, Innovation and Employment (2012). Core Tourism Dataset http://www.infotools.com/MEDviewer/?PageLocation=MED/CubePages/MED_IVA_DepartureDest ination.

Mochizuki, Y., \& Bryan, A. (2015). Climate Change Education in the Context of Education for Sustainable Development: Rationale and Principles. Journal of Education for Sustainable Development, 9(1), 4-26.

Nicholson-Cole, S.A. (2005). Representing climate change futures: a critique on the use of images for visual communication. Computers, Environment and Urban Systems, 29, 255-273.

Notre Dame Global Adaptation Index (2014). Notre Dame, South Bend, IN.

Nowak, J-J \& Sahli, M. (forthcoming). Le tourisme, un atout pour les pays du Sud? Cahiers Français, 393.

Patz, J., Campbell-Lendrum, D., Holloway, T., \& Foley, J. (2005). Impact of Regional Climate Change on Human Health. Nature, 438, 310-317.

Pearson, D. R., \& Beckham, J. (2005). Negligent liability issues involving colleges and students: balancing the risks and benefits of expanded programs and heightened supervision. NASPA Journal, 42(4), 460-477. 
Penfold, P. (2009). Learning Through the World of Second Life-A Hospitality and Tourism Experience. Journal of Teaching in Travel \& Tourism, 8(2-3), 139-160.

Pruneau, D., Gravel, H., Bourque, W., \& Langis, J. (2003). Experimentation with a socio-constructivist process for climate change education. Environmental Education Research, 9(4), 429-446.

Reisinger, A. (2009). Climate Change 101: An educational resource. Wellington: Institute of Policy Studies and New Zealand Climate Change Research Institute, School of Government, Victoria University of Wellington.

Rosenzweig, C., \& Parry, M. (1994). Potential Impact of Climate Change on World Food Supply. Nature, 367, 133-138.

Sausen, R., Isaksen, I., Grewe, V., Hauglustaine, D., Lee, D.S., Myhre, G., Köhler, M.O., Pitari, G., Schumann, U., Stordal, F., Zerefos, C. (2005). Aviation radiative forcing in 2000: and update on IPCC (1999). Meteorologische Zeitschrift, 114, 555-561.

Scarce, R. (1997). Field trips as short-term experiential education. Teaching Sociology, 25(3), 219217.

Schott, C. (2015) 'Digital Immersion for Sustainable Tourism Education: A roadmap to virtual fieldtrips' in Moscardo, G. and Benckendorff, P. (eds) Education for Sustainability in Tourism - A Handbook of Processes, Resources and Strategies (213-227). Berlin: Springer.

Schott, C., Reisinger, A., \& Milfont, T.L. (2010). Tourism and Climate Change: Interrelationships and Implications. In Schott, C. (Ed.), Tourism and the implications of climate change: Issues and actions (1-24). Bingley: Emerald Publishing. 
Schott, C., \& Sutherland, K. A. (2009). Engaging Tourism Students Through Multimedia Teaching and Active Learning. Journal of Teaching in Travel \& Tourism, 8(4), 351-371.

Schott, C., Thomson, A. P., \& Marshall, S. (2015). Cutting edge digital immersion for experiential learning. CAUTHE 2015: Rising Tides and Sea Changes: Adaptation and Innovation in Tourism and Hospitality, 697.

Schreiner, C., Henriksen, E. K., \& Hansen, P. J. K. (2005). Climate education: Empowering today's youth to meet tomorrow's challenges. Studies in Science Education, 41(1), 3-49.

Scott, D., Hall, C. M., \& Gössling, S. (2012). Tourism and Climate Change: Impacts, Adaptation and Mitigation. London: Routledge.

Sheldon, P. J., Fesenmaier, D. R., \& Tribe, J. (2011). The Tourism Education Futures Initiative (TEFI): Activating Change in Tourism Education. Journal of Teaching in Travel \& Tourism, 11(1), $2-23$.

Sheppard, S.R.J. (2005). Landscape visualisation and climate change: the potential for influencing perceptions and behaviour. Environmental Science \& Policy, 8, 637-654.

Singh R.B.K., Hales S., de Wet N., Raj R., Hearnden M., \& Weinstein P. (2001). The influence of climate variation and change on diarrheal disease in the Pacific islands. Environmental Health Perspectives, 109, 155-159.

Stainfield, J., Fisher, P., Ford, B., \& Solem, M. (2000). International virtual field trips: a new direction? Journal of Geography in Higher Education, 24(2), 255-262. 
Statistics New Zealand (2016). International Travel and Migration

http://www.stats.govt.nz/browse_for_stats/population/Migration/international-travel-and-migration-

$\underline{\text { info-releases.aspx }}$

Swim, J., Clayton, S., Doherty, T., Gifford, R., Howard, G., Reser, J., Weber, E. (2010). Psychology and global climate change: Addressing a multifaceted phenomenon and a set of challenges. A report of the American Psychological Association Task Force on the Interface Between Psychology and Global Climate Change. Washington, DC: American Psychological Association.

Turney, C. S. M., Robinson, D., Lee, M., \& Soutar, A. (2009). Using technology to direct learning in higher education: The way forward? Active Learning in Higher Education, 10(1), 71-83.

United Nations World Tourism Organisation, United Nations Environment Program and World Meteorological Organisation (2008). Climate Change and Tourism: Responding to Global Challenges. Madrid: United Nations World Tourism Organization.

Urry, J. (2011). Climate Change and Society. Polity.

Wilkes, A. (2012). Personal communication. Wellington: Victoria University of Wellington.

Wlodkowski, R. J. (2011). Enhancing Adult Motivation to Learn: A Comprehensive Guide for Teaching All Adults. John Wiley \& Sons.

Wright, M. C. (2000). Getting more out of less: The benefits of short-term experiential learning in undergraduate sociology courses. Teaching Sociology, 28(2), 116. 
